\title{
Comparing the Attitudes of Middle and High School Daters in Morocco: A Cross Sectional Study
}

\author{
Soukaina El Kinany ${ }^{1}$, Khaoula Elkinany ${ }^{2}$ \\ ${ }^{1}$ Ph.D. Student, Sidi Mohamed Ben Abdellah University, College of Literature and Human Sciences \\ ${ }^{2}$ Ph.D. Student, Sidi Mohamed Ben Abdellah University, School of Medicine and Pharmacy
}

\begin{abstract}
The present paper aimed at revealing Moroccan teenagers attitudes about dating in Morocco via a cross-sectional study conducted among a population of 100 Moroccan male and female secondary school students in Fez city. Anonymous self-administered questionnaires were of a great utility considering the sensitive nature of the topic. The percentage of middle school students who participated in the study was $47 \%$ compared to 53\% of high schoolers. Most Middle school participants (96\%) were 15 years old. About 71,4\% of their fathers had a university level, and $75 \%$ of mothers had a secondary school level. Most parents (66.7\%) were separated (the father was away), and 39.8\% lived with members of family other than their parents (with aunts or uncles). Concerning high schoolers, most participants (52.9\%) were 17 years old. As many as $80 \%$ of fathers and $73.8 \%$ of mothers were illiterate. Regarding parents' marital status, $66.7 \%$ were widowed. A large number (63.3\%) of students lived with both parents. The findings revealed that more females than males from middle school $66.7 \%$ vs. $47.1 \%$ ) considered that their religiosity was a strong obstacle to dating. About $64.7 \%$ of males agreed relatively that girls who date are not respectful $\left(p=10^{-2}\right)$. Most males from both categories agreed that females who date a lot are unmarriageable (70 \% from high school and $52.9 \%$ from middle school) $\left(p=10^{-2}\right)$. When asked if dating works best when girls please boys, a large number of male middle and high schoolers adopted favourable attitudes $(58.8 \%$ and $56.7 \%$ respectively). Overall, participants' attitudes can be predictors of violence among male middle and high schoolers.
\end{abstract}

Key words: Dating, Attitudes, Middle and High Schoolers, Morocco (Fez city).

\section{Background}

Teen or adolescent dating violence has always been discussed in the light of related concepts, such as relationship violence, gender-based violence, intrapersonal violence, and domestic violence. The various perception of teen dating violence among researchers made it difficult to shape a unified definition of the concept. Janet A. Sigal and Florence L. Denmark (2013), account that dating violence has been understood variously across cultures and countries. In Japan, for instance, dating violence is considered as a form of harassment. In South Africa, and Thailand, however, adolescents do not stand up to physical abuse in dating relationships because it's conceived as a sign of love [1].

Indeed, gender attitudes are a major factor influencing partner violence. The study of gender attitudes is crucial in fact for the early detection of violence, and highly entailed for the understanding of community response to such practices [2]. Most intimate violence is perpetrated by males [3]; males more likely than females adopt hostile gender attitudes and tend to minimize the effects of violence against women [4], [5]. Equally important, societies with gender inequalities contributes to the gap in gender attitudes [6]. Partner violence is likely to be supported and reinforced by cultures that generate patriarchal norms, for instance believing that a male has a right to "correct" or discipline the female behavior as it is the case in India, Nigeria and, China or assuming that girls are responsible for provoking men's sexual urges as in South Africa [7].

Adolescents are more likely to adopt violence supportive attitudes, as they struggle to meet social expectations. Teens may sometimes mistake masculinity for violence and mix between femininity and passivity. Flood (2007) assures that patterns of physical and sexual violence are evident in some young people's intimate relations [8]. In this regard, the present paper aims at comparing middle and high schoolers attitudes of dating in Morocco. The practice of dating is omni-present among younger generations. Still, with the patriarchal luggage of gender inequalities and in the absence of sexual education in schools and among families, Moroccan daters 
are at risk of dating perpetration and victimization. It is assumed that male middle schoolers hold more gender hostile attitudes than females. We also assume that female middle schoolers are more conservative than males and that there are other socio-demographic characteristics, on the top of which education, that influence gender attitudes about relationships.

\section{Methods}

\subsection{Study design}

A cross-sectional study was conducted in 2015 in one middle and one high public schools. Both institutions were situated in poor areas. The middle school location was in an urban area in Fez city; while, the high school was in a rural setting (Moulay Yaacoub , $21.7 \mathrm{~km}$ away from the city).

\subsection{Data Collection}

The questionnaire collected information on participants' socio-demographic characteristics, (mainly sex, age, participants as well as parents' education, parents' marital status, and family income).Data on participants' lifetime dating experience, dating status, and dating attitudes were also included. The anonymous selfadministered questionnaires were distributed in the classrooms during a regular class period, and were filled by participants in the absence of teachers. The Participation was voluntary and students stated their oral consent before filling the forms. The Researchers and investigators in charge of questionnaires distribution indeed provided explanations on the filling instructions and to the participants when needed.

\subsection{Assessment}

The data entry stage started immediately after data collection. Data were entered into MS Windows Excel in the form of codes, and transferred to the Statistical Package for EPI INFO software version 7 (free downloaded from internet). Data analysis involved descriptive as well as inferential statistics. A simple descriptive analysis was done for the variables of interest. Prevalence with 95\% confidence intervals (95\% CI) was also estimated. Odds ratios, along with 95\% confidence intervals, were calculated. Differences in proportions were assessed by the Chi-square test. $\mathrm{P}$ values of $<0.05$ were considered as statistically significant.

\section{Results}

\subsection{Socio-Demographic Characteristics}

All findings were sub-divided into two categories (middle and high school) to achieve the comparison between male and females from both educational levels.

\subsubsection{Middle school Students}

The percentage of middle school students who participated in the study was $47 \%$. Males consisted $34 \%$ of middle school students; while, females were 66\%. Most participants (96\%) were 15 years old. Concerning fathers' education, most fathers $(71,4 \%)$ had a university level. Indeed, $64 \%$ had completed a secondary level; whereas, $48,8 \%$ had a primary educational level, and finally $20 \%$ were illiterate. By the same token, $75 \%$ of mothers had a secondary school level, $71.4 \%$ had a university level, $51.6 \%$ had a primary level, and $26.2 \%$ were illiterate. Most parents (66.7\%) were separated - the father was away- , 46.5\% of participants' parents were married, $42.9 \%$ were divorced, and $33.3 \%$ were widowed. Regarding family income, $57.1 \%$ earned more than $20.000 \mathrm{Dh}$ per month, 50\% earned between 10.000Dh and 20.000Dh, 48.3\% had an income of less than 3000Dh, and $45 \%$ collected between $3000 \mathrm{Dh}$ and $10.000 \mathrm{Dh}$ a month. Although $36.7 \%$ lived with both parents, as many as $39.8 \%$ of participants lived with members of family other than their parents, with aunts or uncles, for instance.

\subsubsection{High School Students}

The percentage of high school students who participated in the study was $53 \%$. Male formed $60 \%$ of middle school students; whereas, the percentage of female participants was 40\%. Most participants (52.9\%) were 17 years old. As many as $80 \%$ of fathers were illiterate, $51.2 \%$ had a primary level, $36 \%$ had a secondary school 
level, and $28.6 \%$ had a university level. As for mothers' education, $73.8 \%$ were illiterate, $48.8 \%$ had a primary level, $25 \%$ had a secondary school level, and $28.6 \%$ had a university level. Regarding parents' marital status, $66.7 \%$ were widowed, $57.1 \%$ were divorced, $53.5 \%$ were married, and $33.3 \%$ were separated- the father was away. The majority of participants' families $(55 \%)$ had a monthly income ranging from $3000 \mathrm{Dh}$ and $10.000 \mathrm{Dh}$, $51.7 \%$ earned less than 3000DH per month, 50\% earned between $10.000 \mathrm{Dh}$ and $20.000 \mathrm{Dh}$, and $42.9 \%$ earned more than $20.000 \mathrm{Dh}$. A large number $(63.3 \%)$ of students lived with both parents; and only $6.2 \%$ lived with other members of the family.

\subsection{Dating Attitudes}

\subsubsection{Religiosity and Dating:}

TABLE I: Religiosity as an Obstacle to Dating

\begin{tabular}{ccccccccc} 
& \multicolumn{4}{c}{ Middle School } & \multicolumn{3}{c}{ High School } \\
\cline { 2 - 9 } & Males & Females & P & OR & Males & Females & P & OR \\
\hline I agree & $47.1 \%$ & $66.7 \%$ & 0,15 & 0,44 & $70 \%$ & $84.2 \%$ & 0,21 & 0,43 \\
I disagree & $52.9 \%$ & $33.3 \%$ & & & $30 \%$ & $15.8 \%$ & &
\end{tabular}

As illustrated in Table (1), more females than males from middle school (66.7\% vs. $47.1 \%)$ considered that their religiosity was a strong obstacle to dating. Similarly, a large number of females $(84.2 \%)$ from high school strongly agreed that the practice of dating was incompatible with their religiosity. Notably, only $15.8 \%$ of female high schoolers disagreed strongly with the statement conversely to $30 \%$ of male high schoolers. Obviously, the notion of conservatism is Omni-present among female participants from both categories.

\subsubsection{Attitudes about male and female daters}

TABLE II: Girls who date are not respectable

\begin{tabular}{lllllllll} 
& \multicolumn{2}{l}{ Middle School } & \multicolumn{5}{l}{ High School } \\
\cline { 2 - 9 } & Males & Females & P & OR & Males & Females & P & OR \\
\hline I agree & $64.7 \%$ & $39.3 \%$ & \multirow{2}{*}{$10^{-2}$} & 2.83 & $43.3 \%$ & $52.6 \%$ & 0.36 & 0,68 \\
I disagree & $35.3 \%$ & $60.7 \%$ & & & $56.7 \%$ & $47.4 \%$ & & \\
\hline \hline
\end{tabular}

Table (2) indicated that the majority of participants who had a negative impression of female daters were male middle schoolers. In high school, $43.3 \%$ of males agreed with the statement; nevertheless, as many as $56.7 \%$ were against it. An important percentage of high school females (60.7\%) also reported their disagreement. Overall, the stated attitude was positively associated with male middle schoolers and vice versa for their female counterparts. Moreover, no significant association was tracked down among high schoolers.

TABLE III: Males who date a lot are Virile

\begin{tabular}{lllllllll} 
& \multicolumn{2}{l}{ Middle School } & \multicolumn{5}{l}{ High School } \\
\cline { 2 - 8 } & Males & Females & P & OR & Males & Females & P & OR \\
\hline I agree & $17.6 \%$ & $26.9 \%$ & \multirow{2}{*}{0,37} & 0,58 & $34.5 \%$ & $5.3 \%$ & $10^{-2}$ & 9,47 \\
I disagree & $82.4 \%$ & $73.1 \%$ & & & $65.5 \%$ & $94.7 \%$ & & \\
\hline \hline
\end{tabular}

In response to the statement that "males who date several girls are virile", a large number of male and female middle schoolers $(82.4 \%$ and $73.1 \%)$ reported their disapproval. Remarkably, $94.7 \%$ of female high schoolers had also disagreed with the statement contrariwise to $34.5 \%$ of male supporters. In fact, the studied attitude was negatively associated with the majority of male and female high schoolers.

TABLE IV: Females who Date a lot are Unmarriageable

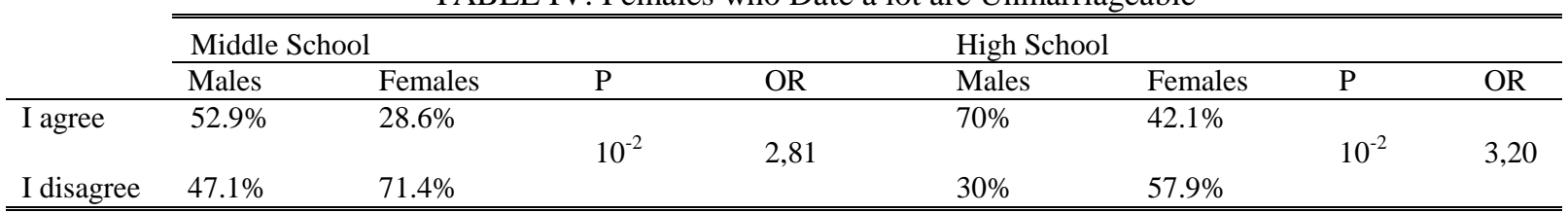


As displayed in table (4), most males from both categories agreed that females who date a lot are unmarriageable (70 \% from high school and 52.9\% from middle school). Equally important, $71.4 \%$ of female middle schoolers strongly disagreed with the idea contrary to $42.1 \%$ of female high schoolers who also expressed their agreement with the statement. Here, males were positively associated with the statement unlike females from both educational levels.

TABLE V: Dating Relationships Work Best When Girls Please Boys

\begin{tabular}{lllllllll} 
& \multicolumn{2}{l}{ Middle School } & \multicolumn{5}{c}{ High School } \\
\cline { 2 - 8 } & Males & Females & P & OR & Males & Females & P & OR \\
\hline I agree & $58.8 \%$ & $33.3 \%$ & \multirow{2}{*}{$10^{-2}$} & 2,85 & $56.7 \%$ & $26.3 \%$ & $10^{-2}$ & 3,66 \\
I disagree & $41.2 \%$ & $66.7 \%$ & & & $43.3 \%$ & $73.7 \%$ & & \\
\hline \hline
\end{tabular}

When asked if dating works best when girls please boys, a large number of male middle and high schoolers adopted favourable attitudes $(58.8 \%$ and $56.7 \%$ respectively). Female middle and high schoolers expressed their opposition $(66.7 \%$ and $73.7 \%)$. Still, the percentage of female opponents rose in consonance to education; the percentage of female high schoolers was relatively higher than middle schoolers. This attitude was associated positively with most males from middle and high school and negatively with females from both educational levels $\left(\mathrm{P}=10^{-2}\right)$.

TABLE VI: Girls Deserve Beating If They Cheated On Their Boyfriends

\begin{tabular}{lllllllll} 
& \multicolumn{2}{l}{ Middle School } & \multicolumn{5}{c}{ High School } \\
\cline { 2 - 8 } & Males & Females & P & OR & Males & Females & P & OR \\
\hline I agree & $70.6 \%$ & $63.3 \%$ & \multirow{2}{*}{0.43} & 1.38 & $87.9 \%$ & $45 \%$ & $10^{-3}$ & 8,86 \\
I disagree & $29.4 \%$ & $36.7 \%$ & & & $12.1 \%$ & $55 \%$ & & \\
\hline \hline
\end{tabular}

The findings presented above showed that the majority of males from both educational levels $(70.6 \%$ from middle school and $87.9 \%$ from high school) agreed that females deserve beating in the case of betrayal. Surprisingly, a high number of female middle schoolers $(63.3 \%)$ approved of such an attitude. In fact, the studied attitude was positively associated with male high schoolers $\left(\mathrm{P}=10^{-3}\right)$, meaning that male high schoolers are at a high risk of violence perpetration $(\mathrm{OR}=8.86)$.

TABLE VII: It's Okay for Males to Slap Females out Of Jealousy

\begin{tabular}{lllllllll} 
& \multicolumn{2}{l}{ Middle School } & \multicolumn{5}{c}{ High School } \\
\cline { 2 - 8 } & Males & Females & P & OR & Males & Females & P & OR \\
\hline I agree & $58.8 \%$ & $40 \%$ & \multirow{2}{*}{0.17} & 2.14 & $48.5 \%$ & $25 \%$ & $10^{-2}$ & 2,82 \\
I disagree & $41.2 \%$ & $60 \%$ & & & $51.5 \%$ & $75 \%$ & &
\end{tabular}

As indicated by the findings, an important percentage of male middle schoolers (58.8\%) said it is okay for males to slap female partners out of jealousy conversely to $60 \%$ of girls from the same educational level. Concerning high schoolers, high percentages of males and females were against the act of slapping girlfriends because of boyfriends' jealousy. This attitude was highly associated with high schoolers $\left(\mathrm{p}=10^{-2}\right)$; that is to say that females were two times protected.

TABLE VIII: It's Okay for Males to Hit Females to Correct Their Behaviours

\begin{tabular}{llllllll} 
& \multicolumn{2}{l}{ Middle School } & \multicolumn{5}{l}{ High School } \\
\cline { 2 - 8 } & Males & Females & $\mathrm{P}$ & OR & Males & Females & P \\
\hline I agree & $70.6 \%$ & $86.7 \%$ & \multirow{2}{*}{0.16} & 0.36 & $75.8 \%$ & $50 \%$ & \multirow{2}{*}{ OR } \\
I disagree & $29.4 \%$ & $13.3 \%$ & & & $24.2 \%$ & $50 \%$ & 3.12 \\
\hline \hline
\end{tabular}

Concerning the use of violence for girls discipline, as many as $70 \%$ of males from both levels agreed with the statement. Equally important, more females than males in middle school were for female battering. A positive association was detected amid male high schoolers $\left(\mathrm{P}=10^{-2} ; \mathrm{OR}=3,12\right)$. 


\subsubsection{Multi-Variate Analysis}

TABLE IX: Middle Schoolers Attitudes about Male and Female Daters

\begin{tabular}{|c|c|c|c|c|}
\hline \multirow[b]{2}{*}{ Gender Attitudes about Male and Female Daters } & \multirow[t]{2}{*}{ Sig. } & \multirow[t]{2}{*}{ Exp (B) } & \multicolumn{2}{|c|}{ IC For Exp (B) $95 \%$} \\
\hline & & & Inferior & Superior \\
\hline Females who date a lot are not respectable &, 131 & 1,697 &, 854 & 3,370 \\
\hline Females who date a lot are unmarriageable &, 305 & 1,433 &, 720 & 2,851 \\
\hline $\begin{array}{l}\text { Dating relationships work best when girls please } \\
\text { boys }\end{array}$ &, 100 & 1,757 & ,898 & 3,437 \\
\hline
\end{tabular}

None of the attitudes above had a great influence on middle schoolers, which could be relegated to the small sample size. All the same, the three attitudes were risk factors of violence for daters in the middle school category.

TABLE X: High Schoolers Attitudes About Male And Female Daters

\begin{tabular}{|c|c|c|c|c|}
\hline \multirow{2}{*}{ Gender Attitudes about Male and Female Daters } & \multirow[t]{2}{*}{ Sig. } & \multirow[t]{2}{*}{$\operatorname{Exp}(B)$} & \multicolumn{2}{|c|}{ IC For Exp (B) $95 \%$} \\
\hline & & & Inferior & Superior \\
\hline Males who date a lot are virile & ,036 & 5,385 & 1,112 & 26,079 \\
\hline $\begin{array}{l}\text { Girls deserve beating if they cheated on their } \\
\text { boyfriends }\end{array}$ &, 013 & 4,804 & 1,399 & 16,497 \\
\hline Girls and boys pleasing & ,399 & 1,491 &, 589 & 3,772 \\
\hline Females who date are unmarriageable &, 041 & 2,670 & 1,041 & 6,851 \\
\hline $\begin{array}{l}\text { It's okay for males to hit females to correct their } \\
\text { behaviours }\end{array}$ & ,404 & 1,542 &, 557 & 4,271 \\
\hline $\begin{array}{l}\text { It's okay for males to slap females out of } \\
\text { jealousy }\end{array}$ & ,399 & 1,545 &, 562 & 4,253 \\
\hline
\end{tabular}

According to the above findings, not all attitudes were positively associated with high schoolers, only three proved significant. Multivariate analyses demonstrated that the most common and influential attitudes among high schoolers were: "Males who date a lot are virile", "Girls deserve beating if they cheated on their boyfriends", and "Females who date are unmarriageable". In other words, the three attitudes were strong predictors of violence.

\section{Discussion}

Contrary to our assumptions, violence supportive attitudes were more common among high schoolers than in middle schoolers. In the same way, male daters had more women hostile attitudes than females. Eventually, education is not a preventive factor against dating violence among males in Morocco; instead, there are other factors influencing daters' perceptions of romantic relationships.

Gender discrimination is a risk factor for girls' victimization in romantic relationships [9]. In Morocco, gender discrimination starts at an early age as Moroccan families bring up girls to serve their brothers and learn how to do house chores while males enjoy a comfortable childhood. Girls' socialization eventually aims at training females to become future housewives [10]. Until the twentieth century, the idea of the adolescent unmarried woman was new in the Muslim world; girls were married off as soon as they reached puberty for fear of getting involved in mixed-sex relationships and stigmatizing the honor of the family [11], which explains females' high sense of conservatism and males' scornful perception of female daters.

The gender gap in violence supportive attitudes can also be relegated to participants' acceptance of violence. Media and peers have a great influence on exaggerating teens' perception of gender roles. Due to their limited experience, female teens are likely to accept violence as integral in relationships while interpreting jealousy and abuse as signs of love [12]. Internet, moreover, conjures up as another social foundation that generates critical values about intimate relationships among boys in particular. The latter by means of internet give access easily to pornographic websites. The term "Sex" was being searched mostly by people in Muslim countries, among which Morocco ranked fifth [13]. 
Finally, education- although positively associated with females only in our study - has an enormous influence on reforming participants' attitudes on violence. Previous surveys found that less violence supportive attitudes were detected among males who received higher education than secondary level, and females who had completed education more than secondary level; higher rates of violence against women; on the other hand, were reported in societies characterized by women's lower status [14], [15].

\section{Limitations}

The current paper is not immune to imperfections. First, the dearth of literature on Moroccan teenagers dating behaviour due to the sensitivity of the issue. Moreover, the small sample size of the populations, which constituted a real obstacle during the process of logistic regression analysis especially among middle schoolers.

\section{Acknowledgements}

This work would not have been possible without the guidance and the cooperation of several individuals, and institutions. We are grateful for Sidi Mohamed ben Abdellah college of Literature and human sciences administration for providing researchers with authorizations to facilitate the process of data collection within the schools. We would also like to thank the secondary schools headmasters and teachers for their help, not to mention students for filling the four-page questionnaire.

\section{References}

[1] Sigal, J.A., and Florence L. Denmark, eds. Violence against girls and women: International perspectives. ABC-CLIO, 2013, ch.3, pp.27-29.

[2] Diemer, K. Women's Safety is a Men's Issue: Men's attitudes to violence against women and what that means for men. White Ribbon Research Foundation, December 2014

[3] Tjaden, P., and N. Thoennes. Prevalence, Incidence and Consequences of Violence Against Women Findings From the National Violence Against Women Survey. Washington, DC: U.S. Department of Justice, National Institute of Justice, November 1998, NCJ 172837.

[4] Davis, T. and C. Lee, Sexual Assault: Myths and stereotypes among Australian adolescents. Sex Roles, vol.34, pp. 787-803, June 1996. http://dx.doi.org/10.1007/BF01544316

[5] Xenos, S. and D. Smith, Perceptions of Rape and Sexual Assault Among Australian Adolescents and Young Adults. Journal of Interpersonal Violence, vol.16, pp. 1103-1119, November 2001. http://dx.doi.org/10.1177/088626001016011001

[6] Marium, S. Women's Level of Education and Its Effect on Domestic Violence in Rural Bangladesh. Journal Of Humanities And Social Science, vol. 19, Ver. III, pp. 40-45, May 2014.

[7] WHO. Understanding and Addressing Violence against Women: Intimate Partner Violence, WHO, Geneva, 2012, Available: http://apps.who.int/iris/bitstream/10665/77432/1/WHO_RHR_12.36_eng.pdf

[8] Flood, M. Why violence against women and girls happens, and how to prevent it. Redress, pp.13-19, August 2007.

[9] Vezina, J. and M. Hebert, Risk Factors for Victimization in Romantic Relationships of Young Women: A Review of Empirical Studies and Implications for Prevention. Trauma Violence Abuse, vol. 8, pp. 33-66, January 2007. http://dx.doi.org/10.1177/1524838006297029

[10] Guessous, S. Au Dela de Toute Pudeur. Casablanca, Morocco: Edition Eddif, 2007, ch 1. , pp.15-31.

[11] Mernissi, F. Beyond the Veil: Male-Female Dynamics in a Muslim Society, 3rd ed, U.S.A Indiana University Press, 1987, ch.1, pp. 6-29.

[12] Levy, B. (ed.) Dating Violence: Young women in danger. Seattle, WA: Seal Press, 1990.

[13] Sex - Google Trends, December 17, 2011

[14] Heise L, C. Garcia-Moreno, Violence by intimate partners. In: Krug EG, Dahlberg LL, Mercy JA, Zwi AB, Lozano R, eds. World Report on Violence and Health. Geneva, Switzerland: World Health Organization; 2002

[15] Naved, R. T., and L. A. Persson, Factors associated with spousal physical violence against women in Bangladesh. Studies in Family Planning, vol. 36, pp. 289-300, 2005.

http://dx.doi.org/10.1111/j.1728-4465.2005.00071.x 